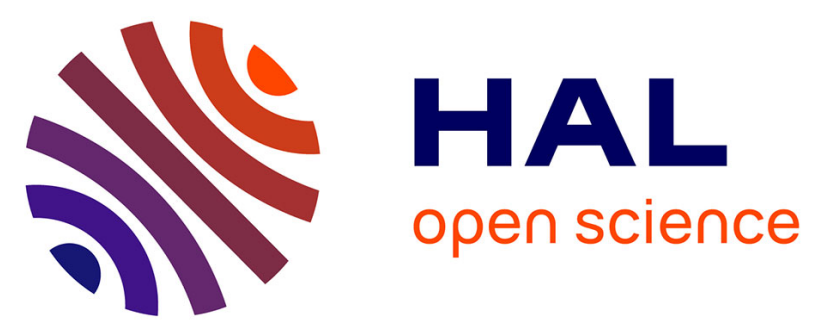

\title{
Influence of the postsynthesis preparation procedure on catalytic behaviour of Ag-loaded BEA zeolites in the hydrodechlorination of 1,2-dichloroethane into value added products
}

\author{
A. Śrębowata, R. Baran, G. Slowik, D. Lisovytskiy, Stanislaw Dzwigaj
}

\section{To cite this version:}

A. Śrębowata, R. Baran, G. Slowik, D. Lisovytskiy, Stanislaw Dzwigaj. Influence of the postsynthesis preparation procedure on catalytic behaviour of Ag-loaded BEA zeolites in the hydrodechlorination of 1,2-dichloroethane into value added products. Applied Catalysis B: Environmental, 2016, 199, pp.514-522. 10.1016/j.apcatb.2016.06.060 . hal-01346265

\section{HAL Id: hal-01346265 \\ https://hal.sorbonne-universite.fr/hal-01346265}

Submitted on 18 Jul 2016

HAL is a multi-disciplinary open access archive for the deposit and dissemination of scientific research documents, whether they are published or not. The documents may come from teaching and research institutions in France or abroad, or from public or private research centers.
L'archive ouverte pluridisciplinaire HAL, est destinée au dépôt et à la diffusion de documents scientifiques de niveau recherche, publiés ou non, émanant des établissements d'enseignement et de recherche français ou étrangers, des laboratoires publics ou privés. 
Influence of the postsynthesis preparation procedure on catalytic behavior of Ag-loaded BEA zeolites in the hydrodechlorination of 1,2-dichloroethane into value added products

A. Śrębowata ${ }^{1, *}$, R. Baran ${ }^{2,3,4}$, G. Słowik ${ }^{5}$, D. Lisovytskiy ${ }^{1}$, S. Dzwigaj $^{3,4, *}$

${ }^{1}$ Institute of Physical Chemistry, PAS, Kasprzaka 44/52, PL-01224 Warszawa, Poland,

${ }^{2}$ AGH University of Science and Technology al. A. Mickiewicza 30, 30-059 Krakow, Poland

${ }^{3}$ Sorbonne Universités, UPMC Univ Paris 06, UMR 7197, Laboratoire de Réactivité de Surface, F-75005, Paris, France

${ }^{4}$ CNRS, UMR 7197, Laboratoire de Réactivité de Surface, F-75005, Paris, France

${ }^{5}$ Faculty of Chemistry, Department of Chemical Technology, Maria Curie - Skłodowska University, Plac Marii Curie - Skłodowskiej 3, PL-20-031 Lublin, Poland

\section{*Corresponding authors}

Anna Srebowata, E-mail: $\quad$ asrebowata@ ichf.edu.pl, $\quad$ Tel. 481223433320

Dzwigaj Stanislaw, E-mail : stanislaw.dzwigaj@upmc.fr, Fax : 33144272113

\section{Graphical Abstract}

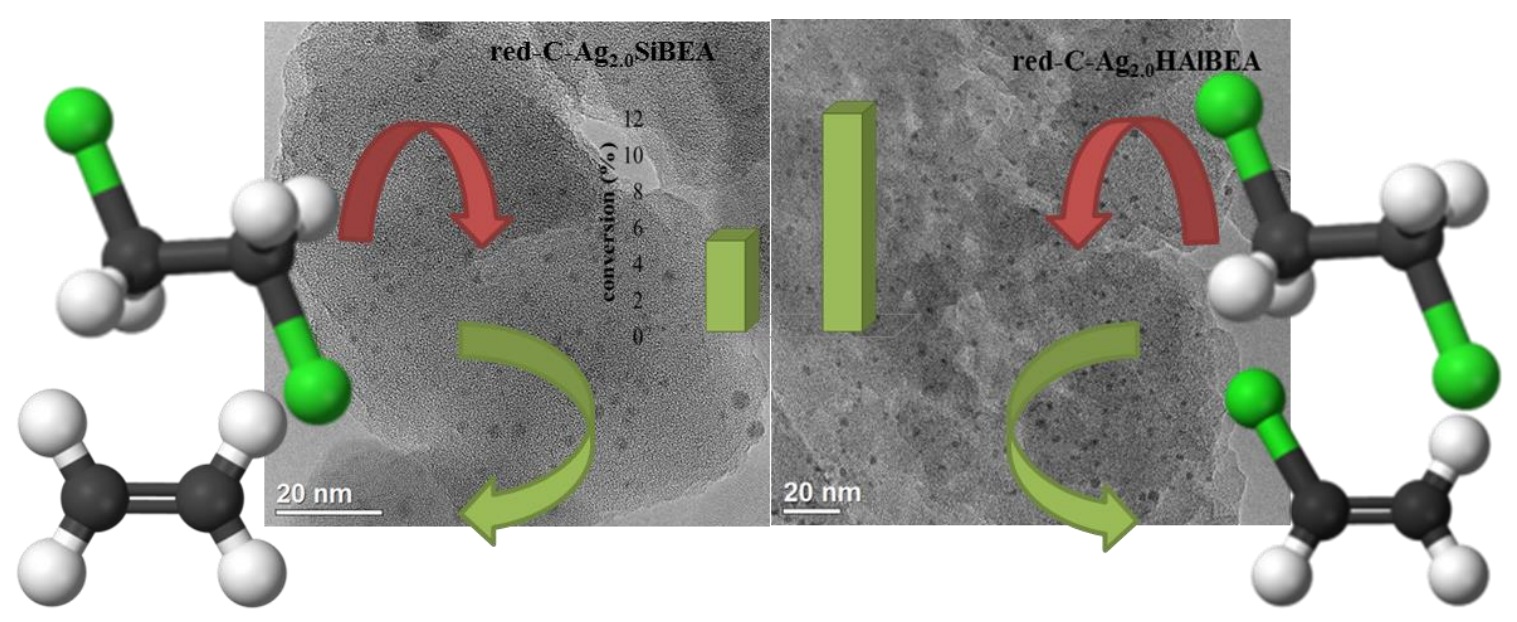




\title{
Highlights
}

- Unique activity of Ag-loaded BEA zeolites in hydrodechlorination of 1,2-dichloroethane

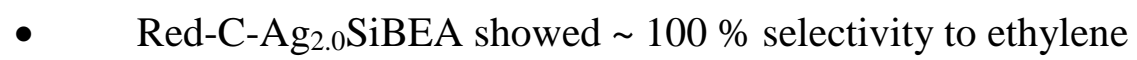

- $\quad$ Activity of red-C-Ag2.0HAlBEA depended on their acidity

- $\quad$ Red-C-Ag $\operatorname{Ag}_{2.0} \mathrm{HAlBEA}$ promoted formation of $\sim 100 \%$ of vinyl chloride

- $\quad$ Only large $\mathrm{Ag}$ nanoparticles transform into $\mathrm{AgCl}$ upon $\mathrm{HDC}$ reaction

\begin{abstract}
Two silver-containing BEA zeolites prepared by a two-step postsynthesis method $\left(\mathrm{Ag}_{2.0} \mathrm{SiBEA}\right)$ and a conventional wet impregnation $\left(\mathrm{Ag}_{2.0} \mathrm{HAlBEA}\right)$ showed a high activity in the conversion of 1,2-dichloroethane (1,2-DCE) into value added products with 100\% selectivity into ethylene and $100 \%$ selectivity into vinyl chloride, respectively. The role of the silver in two kinds of studied catalysts was different. The HRTEM, STEM with EDS elemental mapping showed that the excellent activity of silver containing catalyst, prepared by two-step postsynthesis method, in hydrodechlorination of 1,2-DCE was strongly related to the presence of very small $(<3 \mathrm{~nm})$ metallic nanoparticles, resistant for the deactivation by chlorine poisoning. On the other hand, introduction of Ag ions into the HAlBEA zeolite led to
\end{abstract}


a decrease of the coke formation during hydrodechlorination process on red-C- $\mathrm{Ag}_{2.0} \mathrm{HAlBEA}$ zeolite catalyst. As a result, it was observed lower drop of activity of red-C-Ag ${ }_{2.0} \mathrm{HAlBEA}$ catalyst than HAlBEA over HDC reaction was observed with maintaining $100 \%$ selectivity to vinyl chloride.

Keywords: Ag, zeolite, 1,2-dichloroethane, hydrodechlorination, value added products

\section{Introduction}

One of the most important environmental problems is contamination of the atmosphere, the soil and the ground water by chlorine containing volatile organic compounds (Cl-VOCs). Due to the high volatility and resistance to degradation they pose a serious threat to the human health and life. Therefore, there is needed a new technology that would efficiently remove these harmful, usually mutagenic and carcinogenic chemicals from environment [1].

An attractive, environmentally friendly method of "utilization" of Cl-VOC's is hydrodechlorination (HDC). The interest in this method has increased since the early nineties of $20^{\text {th }}$ century. [2]. In the contrast to the combustion of Cl-VOCs $[3,4]$, catalytic oxidation [5], plasma destruction [6], pyrolysis [7] and HDC lead to the formation of useful and/or environmentaly friendly products. It was reported that the efficient catalysts in hydrodechlorination are noble metals such as palladium and platinum [8-12] and noble metals doped with $\mathrm{Co}, \mathrm{Cu}, \mathrm{Ni}, \mathrm{Fe}$ or $\mathrm{Ag}$ [13-20]. Notwithstanding, as an alternative to expensive precious-metals-supported catalysts, it has been proposed to use containing catalysts, which also lead to high selectivity to value added products [21-24]. Depending on the kind of the support, application of nickel containing materials leads to the formation of unsaturated hydrocarbons and/or less chlorinated hydrocarbons, such as ethylene and vinyl chloride in the case of HDC of 1,2-dichloroethane [20,21].

Ag-supported catalysts have been extensively used in $\mathrm{NO}_{\mathrm{x}}$ abatement [25], the selective catalytic reduction of NO [26], the selective catalytic oxidation of ammonia [27], CO 
oxidation [28] or ethylene epoxidation [29] as well as in hydrogenation of $\mathrm{C}=\mathrm{O}$ groups in the presence of a $\mathrm{C}=\mathrm{C}$ bond [30]. Moreover, silver plays also very important role in bimetallic catalytic systems [31,32]. For example, the bimetallic catalyst based on palladium with addition of silver was applied for selective hydrodechlorination of 1,2-dichloroethane [32].

Our thorough analysis of the literature data did not unearth any studies of catalytic activity of monometallic silver catalysts in 1,2-dichloroethane hydrodechlorination. However, our recent work on the activity of zeolite containing bimetallic Ni-Ag systems showed unexpected activity of monometallic silver-containing BEA zeolite catalyst in HDC reaction [33]. We postulated that this unique activity of $\mathrm{Ag}$ is related to the presence of very small $\operatorname{Ag}(0)$ nanoparticles. Therefore, the aim of this study is the detailed examination of the eauses reasons of the high activity of red-C-AgSiBEA catalyst and the investigation of the influences of the preparation procedures on the properties of Ag-containing BEA zeolite catalysts in the selective conversion of 1,2-dichloroethane into value added products.

Red-C-Ag ${ }_{2.0} \mathrm{HAlBEA}$ and red-C-Ag ${ }_{2.0} \mathrm{SiBEA}$ zeolites prepared by conventional wet impregnation and two-step postsynthesis procedure, respectively, were characterized by UVVis spectroscopy (DR UV-Vis), temperature-programmed reduction (TPR) and X-ray diffraction (XRD). To determine the nanoparticles size distribution in reduced and spentcatalysts HRTEM, STEM with elemental mapping and phase identification were used.

\section{Experimental}

\subsection{Catalysts synthesis}

A tetraethylammonium BEA (TEABEA) $(\mathrm{Si} / \mathrm{Al}=17$, with $2.7 \mathrm{wt} \%$ of $\mathrm{Al}$ and $44.2 \mathrm{wt}$ $\%$ of $\mathrm{Si}$ ) zeolite provided by RIPP (China) was calcined in air $\left(100 \mathrm{~K} \mathrm{~h}^{-1}\right)$ at $823 \mathrm{~K}$ for $15 \mathrm{~h}$ under static condition to remove the organic template. Organic-free BEA zeolite was separated into two portions. The first portion was treated with $13 \mathrm{~mol} \cdot \mathrm{L}^{-1}$ nitric acid solution 
$(353 \mathrm{~K}, 4 \mathrm{~h})$ to obtain dealuminated $\mathrm{SiBEA}$ zeolite $(\mathrm{Si} / \mathrm{Al}=1500$, with 0.02 wt $\%$ of $\mathrm{Al}$ and 46.6 wt $\%$ of $\mathrm{Si}$ ) and then washed several times with distilled water and dried at $363 \mathrm{~K}$ overnight. Second fraction of calcined BEA zeolite was treated two times with $0.1 \mathrm{~mol} \mathrm{~L}^{-1}$ $\mathrm{NH}_{4} \mathrm{NO}_{3}$ solution during $3 \mathrm{~h}$ in order to exchange $\mathrm{K}^{+}$and $\mathrm{Na}^{+}$ions present in industrial BEA zeolite, for $\mathrm{NH}_{4}{ }^{+}$ion. Then, the solid was washed with distilled water and dried overnight at $363 \mathrm{~K}$. The $\mathrm{NH}_{4} \mathrm{AlBEA}$ sample was calcined in air $\left(100 \mathrm{~K} \cdot \mathrm{h}^{-1}\right)$ for $3 \mathrm{~h}$ at $773 \mathrm{~K}$ under static condition to remove $\mathrm{NH}_{3}$ and obtain acidic form of zeolite BEA, HAlBEA ( $\mathrm{Si} / \mathrm{Al}=20$, with 2.2 wt $\%$ of $\mathrm{Al}$ and $44.2 \mathrm{wt} \%$ of $\mathrm{Si})$.

In order to obtain $\mathrm{Ag}_{2.0} \mathrm{HAlBEA}$ and $\mathrm{Ag}_{2.0} \mathrm{SiBEA}$ zeolites, $2 \mathrm{~g}$ of HAlBEA or SiBEA were impregnated with aqueous solutions of $\mathrm{AgNO}_{3}$, respectively. In an initial stage of the preparation process the suspensions were stirred for $24 \mathrm{~h}$ at ambient temperature in excess solvent. In the following step, samples were stirred in evaporator under vacuum of a water pump for $2 \mathrm{~h}$ in air at $333 \mathrm{~K}$ until water removal.

After that, as prepared $\mathrm{Ag}_{2.0} \mathrm{HAlBEA}$ and $\mathrm{Ag}_{2.0} \mathrm{SiBEA}$ were calcined at $773 \mathrm{~K}$ for $3 \mathrm{~h}$ in air flow $\left(50 \mathrm{~mL} \cdot \mathrm{min}^{-1}\right)$ and labelled as $\mathrm{C}-\mathrm{Ag}_{2.0} \mathrm{HAlBEA}(\mathrm{Si} / \mathrm{Al}=20$, with $2.2 \mathrm{wt} \%$ of $\mathrm{Al}$ and 44 wt $\%$ of $\mathrm{Si}$, and $2.0 \mathrm{wt} \%$ of $\mathrm{Ag})$ and $\mathrm{C}-\mathrm{Ag}_{2.0} \mathrm{SiBEA}(\mathrm{Si} / \mathrm{Al}=1500$, with $0.02 \mathrm{wt} \%$ of $\mathrm{Al}$ and 46.4 wt $\%$ of $\mathrm{Si}$, and 2.0 wt $\%$ of $\mathrm{Ag}$ ), respectively (where $\mathrm{C}$ stand for calcined). Finally, C-Ag ${ }_{2.0} \mathrm{HAlBEA}$ and $\mathrm{C}-\mathrm{Ag}_{2.0} \mathrm{SiBEA}$ materials were reduced at $873 \mathrm{~K}$, for $3 \mathrm{~h}$ in flowing $10 \% \mathrm{H}_{2} / \mathrm{Ar}$ to obtain red-C- $\mathrm{Ag}_{2.0} \mathrm{HAlBEA}$ and red-C- $\mathrm{Ag}_{2.0} \mathrm{SiBEA}$, respectively (where red stand for reduced).

\subsection{Characterization techniques}

DR UV-vis spectra of as prepared, calcined and reduced samples were recorded at ambient atmosphere on a Cary 5000 Varian spectrometer equipped with a double integrator with polytetrafluoroethylene as reference. 
Temperature-programmed reduction (TPR) was carried out using the glass-flow system. TPR runs were conducted in flowing $10 \% \mathrm{H}_{2} / \mathrm{Ar}\left(25 \mathrm{~mL} \cdot \mathrm{min}^{-1}\right)$, ramping the temperature from ambient to $1123 \mathrm{~K}$ with step of $10 \mathrm{~K} \cdot \mathrm{min}^{-1}$ and using a Gow-Mac thermal conductivity detector (TCD). Injections of known amounts of hydrogen into the hydrogen-argon flow were provided for calibration (before and after each TPR run).

X-ray driffractograms (XRD) were recorded in ambient atmosphere on Geigerflex Rigaku-Denki (Japan) diffractometer with nickel filtered and $\mathrm{CuK}_{\alpha}$ radiation. Data acquisition for sample after reduction step and after kinetic run were recorded in the $2 \theta$ range of $5-90^{\circ}$ with step of $0.02^{\circ}$.

HRTEM studies were carried out for containing silver zeolites after reduction and after catalytic tests. The catalysts were grinded in an agate mortar to a fine powder. The resulting powder was suspended in $99.8 \%$ ethanol (POCH) to form a slurry. The sample was inserted into the ultrasonic homogenizer for $20 \mathrm{~s}$. Then, the slurry containing the catalyst was pipetted and supported on a 200 mesh copper grid and stabilized with carbon (Ted Pella Company) and left on the filter paper until the ethanol has evaporated. Subsequently, the sample deposited on the grid was inserted to holder and moved to electron microscope. The electron microscope Titan G2 60-300 kV FEI Company, equipped with: field emission gun (FEG), monochromator, three condenser lenses system, the objective lens system, image correction (Cs-corrector), HAADF detector and EDS spectrometer (Energy Dispersive X -Ray Spectroscopy) EDAX Company with detector $\mathrm{Si}(\mathrm{Li})$ was used to display the prepared catalysts. Microscopic studies of the catalysts were carried out at an accelerating voltage of the electron beam equal to $300 \mathrm{kV}$.

\subsection{Catalysts activity}

The hydrodechlorination reaction (HDC) of 1,2-dichloroethane (1,2-DCE, pure 99,8\% from Sigma-Aldrich, Germany) was carried out with two series of zeolite catalysts: red-C- 
$\mathrm{Ag}_{2.0} \mathrm{HAlBEA}$ and red-C-Ag $2.0 \mathrm{SiBEA}$. Prior to reaction, $0.2 \mathrm{~g}$ of $\mathrm{C}-\mathrm{Ag}_{2.0} \mathrm{HAlBEA}$ and $\mathrm{C}-$ $\mathrm{Ag}_{2.0} \mathrm{SiBEA}$ zeolites were reduced in flowing $10 \% \mathrm{H}_{2} / \mathrm{Ar}\left(25 \mathrm{~mL} \cdot \mathrm{min}^{-1}\right)$, ramping the temperature from 298 to $873 \mathrm{~K}$ (at $10 \mathrm{~K} \cdot \mathrm{min}^{-1}$ ) and kept at $873 \mathrm{~K}$ for $3 \mathrm{~h}$. Subsequently, the catalysts were cooled down into $523 \mathrm{~K}$ and contacted with the reaction mixture $\left(\mathrm{H}_{2}+\mathrm{Ar}+\right.$ 1,2-DCE). Total gas flow was $42 \mathrm{~mL} \cdot \mathrm{min}^{-1} \cdot 1,2-\mathrm{DCE}$ was provided from a saturator kept at $273 \mathrm{~K}$. The partial pressure ratio $\mathrm{p}\left(\mathrm{H}_{2}\right) / \mathrm{p}(1,2-\mathrm{DCE})$ was $1: 1$. The flows of $\mathrm{H}_{2}$ and Ar were fixed by using Bronkhorst Hi-Tec mass flow controllers. The contact time was $\tau=0.7 \mathrm{~s}$ and the space velocity was $\mathrm{SV}=0.0035\left(\mathrm{~m}^{3} \cdot \mathrm{kg}^{-1} \cdot \mathrm{s}^{-1}\right)$. The exhaust gas stream was analyzed with gas chromatography, using a HP 5890 series II Hewlett Packard (USA), gas chromatograph with FID detector, a $5 \%$ Fluorcol/Carbopac B Supelco (USA) column (10 ft). The results of GC analysis were elaborated using HP Chemstation.

\section{Results and discussion}

The state of silver in Ag-containing BEA zeolites was investigated by DR UV-vis and $\mathrm{H}_{2}-\mathrm{TPR}$

\subsection{Diffuse reflectance $U V$-vis investigation}

In general, as reported earlier for Ag/zeolite A [34,35] the electronic structure of a silvercontaining zeolite material can be seen as a superposition of the electronic structure of the framework and the silver species. According to earlier studies [36,37] depending on the state of silver, DR UV-vis adsorption bands appear at wavelength of $210-500 \mathrm{~nm}$. The absorbance in the region below $250 \mathrm{~nm}$ is generally attributed to electronic transitions from $4 \mathrm{~d}^{10}$ to $4 \mathrm{~d}^{9} 5 \mathrm{~s}^{1}$ of highly dispersed $\mathrm{Ag}^{+}$ions. The absorption bands in the range of $250-390 \mathrm{~nm}$ are commonly ascribed to silver clusters $\left(\operatorname{Ag}_{\mathrm{n}}{ }^{\delta+}\right.$ with $\left.\mathrm{n} \leq 8\right)$ with a variety of cluster sizes and/or different oxidation states. The absorption at wavelengths $>370 \mathrm{~nm}$ is attributed to nanoparticles of metallic silver [38]. 
As it is showed in Figure 1 and 2, in DR UV-vis spectra of as prepared $\mathrm{Ag}_{2.0} \mathrm{HAlBEA}$ and $\mathrm{Ag}_{2.0} \mathrm{SiBEA}$ two bands at 214 and $270-305 \mathrm{~nm}$ are present related to the charge transfer transition between $4 \mathrm{~d}^{10}$ and $4 \mathrm{~d}^{9} 5 \mathrm{~s}^{1}$ level of highly dispersed $\mathrm{Ag}^{+}$species and charge transfer transitions in BEA framework, respectively, in line with earlier reports for Ag-MFI zeolites, $\mathrm{Ag} / \mathrm{Al}_{2} \mathrm{O}_{3}, \mathrm{Ag}^{+} / \mathrm{ZSM}-5$ and AgBEA [36,39-42]. The absence of the bands at higher wavelength between 350 and $500 \mathrm{~nm}$ suggests that silver nanoclusters $\left(\operatorname{Ag}_{\mathrm{n}}{ }^{\delta+}\right)$ and metallic silver nanoparticles are not present in as prepared $\mathrm{Ag}_{2.0} \mathrm{HAlBEA}$ and $\mathrm{Ag}_{2.0} \mathrm{SiBEA}$.

The disappearance of the band at $214 \mathrm{~nm}$ and appearance of new bands in the range of $260-520 \mathrm{~nm}$, at 286, 309, 405 and $520 \mathrm{~nm}$ for C-Ag ${ }_{2.0}$ HAlBEA and at 266 and $420 \mathrm{~nm}$ for C$\mathrm{Ag}_{2.0} \mathrm{SiBEA}$ (Figures 1 and 2) may suggest the formation of $\mathrm{Ag}^{\mathrm{n}{ }^{+}}$clusters and silver nanoparticles with different average size diameter under calcination condition $[38,43]$.

Further treatment of $\mathrm{C}-\mathrm{Ag}_{2.0} \mathrm{HAlBEA}$ and $\mathrm{C}-\mathrm{Ag}_{2.0} \mathrm{SiBEA}$ with flowing $10 \% \mathrm{H}_{2} / \mathrm{Ar}$ leads to decrease of the intensity of the bands in the range of $260-420 \mathrm{~nm}$ (Figures 1 and 2) due to the reduction of silver oxide nanoclusters $\left(\mathrm{Ag}_{\mathrm{n}}{ }^{\delta+}\right)$ and formation of $\mathrm{Ag}^{0}$ nanoparticles. New bands appeared at 209, 223, 426 and $520 \mathrm{~nm}$ for red-C-Ag 2.0 HAlBEA and at 209, 223 and $405 \mathrm{~nm}$ for red-C- $\mathrm{Ag}_{2.0} \mathrm{SiBEA}$ are probably related to existence of highly dispersed $\mathrm{Ag}^{+}$ ions $(209 \mathrm{~nm})$ [38] and the formation of $\mathrm{Ag}^{0}$ nanoparticles, in line with earlier report on $\mathrm{Ag}$ containing materials $[37,39]$.

\subsection{Temperature - programmed reduction results}

Temperature-programmed reduction experiments were carried out to determine the reducibility of silver in $\mathrm{C}-\mathrm{Ag}_{2.0} \mathrm{HAlBEA}$ and $\mathrm{C}-\mathrm{Ag}_{2.0} \mathrm{SiBEA}$ zeolites. For both zeolite samples low intense reduction peaks at temperature 313 and $366 \mathrm{~K}$ for $\mathrm{C}-\mathrm{Ag}_{2.0} \mathrm{HAlBEA}$ and at 312 for 
$\mathrm{C}-\mathrm{Ag}_{2.0} \mathrm{SiBEA}$ are observed, respectively, in Figure 3. These low temperature reduction peaks could be assigned to the reduction of well dispersed mononuclear $A g(I)$ and/or silver oxides to metallic $\mathrm{Ag}^{0}$ form, in agreement with earlier works on silver based catalysts [26,44].

Additionally, TPR pattern of C-Ag ${ }_{2.0} \mathrm{HAlBEA}$ contains two main peaks at 466 and 624 $\mathrm{K}$ as well as small one at $765 \mathrm{~K}$. The observed peaks may be attributed to the reduction of silver present in three different states. The first of them can be attributed to the reduction of $\mathrm{Ag}_{2} \mathrm{O}$ present in extra-framework positions. Two reduction peaks with the maximum at higher temperature may be assigned to reduction of silver species $\left(\mathrm{Ag}^{+}\right.$ions $)$at exchange positions and/or strongly interacting with zeolite support (probably two types of silver species) [45].

On the other hand, TPR pattern of $\mathrm{C}-\mathrm{Ag}_{2.0} \mathrm{SiBEA}$ in Figure 3, except low temperature peak, contains two peaks at 645 and 744 K. Similarly, like in the case of the results obtained for $\mathrm{C}-\mathrm{Ag}_{2.0} \mathrm{HAlBEA}$, they could be attributed to reduction of excellent dispersed silver species most probably present as mononuclear isolated $\mathrm{Ag}(\mathrm{I})$. The difference between the position of the peak maximum on TPR patterns for $\mathrm{C}-\mathrm{Ag}_{2.0} \mathrm{HAlBEA}$ and $\mathrm{C}-\mathrm{Ag}_{2.0} \mathrm{SiBEA}$ could be related to the synthesis procedure. For $\mathrm{C}-\mathrm{Ag}_{2.0} \mathrm{SiBEA}$, some part of silver could strongly interact with zeolite support and is more resistant for reduction process.

Although both of Ag-containing zeolites comprise the same Ag content, TPR pattern of $\mathrm{C}-\mathrm{Ag}_{2.0} \mathrm{SiBEA}$ shows lower hydrogen consumption than $\mathrm{C}-\mathrm{Ag}_{2.0} \mathrm{HAlBEA}$. Thanks to injections of known amounts of hydrogen into the hydrogen-argon flow before and after each TPR run, the quantitative estimation of the amount of reduced Ag in the both samples were possible. Calculations obtained for $\mathrm{C}-\mathrm{Ag}_{2.0} \mathrm{SiBEA}$ showed degree of reduction of $78 \%$. On the other hand, the degree of reduction of $100 \%$ was achieved for $\mathrm{C}-\mathrm{Ag}_{2.0} \mathrm{HAlBEA}$. According to Popovych et al. [26], this phenomenon may be caused by the problem of reduction of $\mathrm{Ag}$ incorporated into the framework position of SiBEA and/or the formation of metallic silver nanoparticles during calcination process. 


\subsection{Catalytic activity of red-C-Ag $2.0 H A l B E A$ and red-C-Ag $2.0 S i B E A$}

In the Figure 4 are showed the differences of the 1,2-dichloroethane conversion in hydrodechlorination of 1,2-DCE between all studied catalysts. The catalytic activities of redC-HAlBEA support and red-C-Ag ${ }_{2.0} \mathrm{HAlBEA}$ zeolite catalyst are very similar, in particular during the first hours of the reaction. It suggests that the $\operatorname{Ag}(0)$ nanoparticles present in red-C$\mathrm{Ag}_{2.0} \mathrm{HAlBEA}$ zeolite catalyst did not significant influence on the catalytic properties of this catalyst in hydrodechlorination of 1,2-dichloroethane. The very high ( 100\%) selectivity towards vinyl chloride for both zeolite catalysts indicates (Fig. 5) that transformation of 1,2dichloroethane into vinyl chloride to goes on Brønsted acidic sites numerously present in both zeolites in line with our report on Ni-containing HAlBEA zeolite catalyst and HAlBEA support [21]. On the other hand, it should be noticed here that the activity of red-C$\mathrm{Ag}_{2.0} \mathrm{HAlBEA}$ decreased slower in time than it was observed for red-C-HAlBEA (Fig. 4). This phenomenon is probably related to decrease in the amount of strong Brønsted acidic sites due to partial ion exchange between proton of bridging hydroxyls $\mathrm{Si}-\mathrm{O}(\mathrm{H})-\mathrm{Al}$ groups with silver ions upon introduction of $\mathrm{Ag}$ into the HAlBEA zeolite. Similar observations were already reported in our previous work [42]. Such a zeolite modification resulted in a decrease of the cock formation upon hydrodechlorination process on red-C-Ag ${ }_{2.0} \mathrm{HAlBEA}$ and in the consequence a lower drop of 1,2-dichloroethane conversion.

As it is seen in Figure 4, the activity of dealuminated form of BEA zeolite (red-CSiBEA support) in HDC is negligible with 1,2-dichloroethane conversion of $0.5 \%$. In contrast, red-C-Ag ${ }_{2.0} \mathrm{SiBEA}$ zeolite catalyst shows significant activity in HDC with 1,2dichloroethane conversion of about $4 \%$ and very high selectivity towards ethylene $(100 \%$ during several hours of reaction test (Fig. 6.)). Additionally, red-C-Ag $2.0 \mathrm{SiBEA}$ zeolite catalyst is very stable in hydrodechlorination of 1,2-dichloroethane (Fig. 4) as shown by the 
similar 1,2-dichloroethane conversion during $17 \mathrm{~h}$ of the reaction without signs of deactivation.

In the Figures 5 and 6 the results of selectivity to vinyl chloride and ethylene are showed respectively. Due to the presence of traces of strong Brønsted acidic sites, the main product obtained for red-C-SiBEA was vinyl chloride (Fig. 5) and selectivity towards ethylene was almost zero due to the absence of silver. On the other hand, for red-C$\mathrm{Ag}_{2.0} \mathrm{SiBEA}$ containing well dispersed small $\mathrm{Ag}(0)$ nanoparticles, $100 \%$ selectivity towards ethylene was achieved. Furthermore, the durability experiment with red-C- $\mathrm{Ag}_{2.0} \mathrm{SiBEA}$ showed very high stability of this catalysts and constant selectivity to ethylene during $\sim 67 \mathrm{~h}$ of 1,2-dichloroethane hydrodechlorination (Fig. 7).

The comprehensive review of the literature did not unearth any experimental study of HDC of 1,2-dichloroethane on monometallic silver supported on BEA zeolite. Therefore it is very difficult to compare our results with other works. Presence of silver usually influences catalytic behaviour of noble metals such as $\mathrm{Pd}$ and $\mathrm{Pt}$ in hydrodechlorination $[16,17,49]$. Normally, an addition of $\mathrm{Ag}$ to noble metal ( $\mathrm{Pd}$ or $\mathrm{Pt}$ ) containing catalysts improves ethylene selectivity during HDC of 1,2-dichloroethane, as reported earlier [16,17,49]. Pirard et al. [49] determined the role of silver in the formation of ethylene on ever-bimetallic $\mathrm{Pd}-\mathrm{Ag} / \mathrm{SiO}_{2}$ catalyst. By the using an experimental setup design with five independent variables: (temperature and partial pressures of 1,2-dichloroethane, hydrogen, ethylene and hydrogen chloride) they revealed that hydrodechlorination of 1,2-dichloroethane on $\mathrm{Pd}-\mathrm{Ag} / \mathrm{SiO}_{2}$ correspond to a Langmuir-Hinshelwood model involving two types of active sites and the 1,2-dichloroethane adsorption as rate-determining step. Moreover, they reported that HDC of 1,2-dichloroethane into ethylene occurs on silver sites through dissociative adsorption with successive brakeage of the two $\mathrm{C}-\mathrm{Cl}$ bonds and desorption of ethylene. However, it was postulated that silver necessarily "needs" the source of atomic form of hydrogen, otherwise is 
deactivated by adsorbed chlorine anions $[16,17,20,49]$. In the case of bimetallic palladium silver system this role has been played by $\mathrm{Pd}$, which thanks to its activation power of hydrogen by dissociative chemisorption, supplies hydrogen atoms for the regeneration of the chlorinated silver surface into metallic silver. Thus, the occurrence of Ag and noble metal alloys is crucial in order to obtain active catalyst with very high selectivity toward desired products $[16,17,49]$. The lack of such a system led to the irreversible deactivation of silver sites by chlorine poisoning. Therefore, very good catalytic behaviour of red-C- $\mathrm{Ag}_{2.0} \mathrm{SiBEA}$ may be related to the presence of poison-resistant silver nanoparticles. So it is extremely interesting to find the reason of this unique activity.

It is well known that the catalytic behaviour of different materials in HDC reaction is strongly dependent on metal(s) particles size. Generally, smaller metal particle sizes, and thereby, higher metal surface areas could favourably impact on catalytic activity, selectivity and stability of metal(s)/support systems in HDC [21,50,51]. Due to the very low activity of monometallic silver catalysts in 1,2-dichloroethane hydrodechlorination, authors did not concentrate on determination of the silver particles size [16,17]. However, Pirard et al. [49] postulated that catalytic behaviour of silver containing catalysts in HDC of 1,2-dichloroethane should be attributed to the presence of $\operatorname{Ag}(0)$ nanoparticles with small size. It was indirectly confirmed by Lambert et al. [18] who postulated that the large silver nanoparticles are inactive in hydrodechlorination of 1,2-dichloroethane. Therefore, according to Pirard et al.

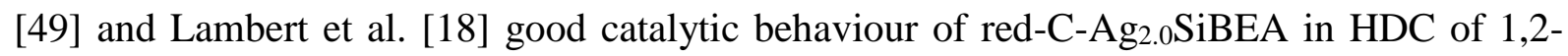
dichloroethane should be attributed to the presence of $\operatorname{Ag}(0)$ nanoparticles with small size. Babu et al. [50] suggested that the presence of smaller Ag nanoparticles promotes electron transfer from metal to the support. Thus, the cationic $\mathrm{Ag}_{\mathrm{n}}{ }^{\delta+}$ clusters are more resistant to deactivation by chlorine adsorption and red-C- $\mathrm{Ag}_{2.0} \mathrm{SiBEA}$ zeolite catalyst remains active during the reaction. The catalytic behaviour of red-C- $\mathrm{Ag}_{2.0} \mathrm{SiBEA}$ is very similar to the one of 
$\mathrm{Au} / \mathrm{Fe}_{2} \mathrm{O}_{3}$ with excellent dispersed gold nanoparticles of average size $2.6 \mathrm{~nm}$ [52]. Although overall conversion obtained for red-C-Ag ${ }_{2.0} \mathrm{SiBEA}$ was slightly smaller or comparable to that obtained for other materials in hydrodechlorination of 1,2-dichloroethane (Figs. 4,7) [8-24], it should be noted that this is the first report where significant activity of monometallic silver nanoparticles formed in zeolite catalyst in HDC process was achieved.

The results of physicochemical characterization and catalytic tests suggest that the active species of 1,2-dichloroethane hydrodechlorination towards ethylene are small and well dispersed silver(0) nanoparticles. On the other hand, transformation of 1,2-dichloroethane into vinyl chloride takes place on Bronsted acidic centers present in red-C-HAlBEA and red-C$\mathrm{Ag}_{2.0} \mathrm{HAlBEA}$. The detailed information of the reaction mechanism was published in our earlier work [21]. The formation of well dispersed $\mathrm{Ag}(0)$ species in red-C-Ag${ }_{2.0} \mathrm{SiBEA}$ was possible due to the application of the two-step postsynthesis method for catalysts preparation. The isolated $\operatorname{Ag}(\mathrm{I})$ species occurring in the framework positions of $\mathrm{C}-\mathrm{Ag}_{2.0} \mathrm{SiBEA}$ were transformed during $\mathrm{H}_{2}$ treatment into small silver(0) nanoparticles.

\subsection{HRTEM and STEM investigation}

The insightful HRTEM, STEM and EDS elemental mapping was carried out to identify silver particles size and to help clarify the cause of unique activity of silver containing zeolites in HDC reaction.

Figures 8 and 9 exhibit HRTEM images and histograms of silver nanoparticles size distribution for red-C-Ag ${ }_{2.0} \mathrm{HAlBEA}$, spent-red-C-Ag $2.0 \mathrm{HAlBEA}$, red-C-Ag ${ }_{2.0} \mathrm{SiBEA}$ and spent-red-C-Ag $2.0 \mathrm{SiBEA}$.

For red-C-Ag $\operatorname{Ag}_{2.0} \mathrm{HAlBEA}$ the silver nanoparticles are well dispersed in the zeolite structure and an average silver particle size is $\sim 4 \mathrm{~nm}$. The silver nanoparticles with the size of 2-6 $\mathrm{nm}$ formed in red-C- $\mathrm{Ag}_{2.0} \mathrm{HAlBEA}$ might be due to incorporation of part of $\mathrm{Ag}^{+}$ions in 
vacant-T-atoms sites of parent HAlBEA support, in line with our earlier work [21]. The results obtained for spent-red-C-Ag $2.0 \mathrm{HAlBEA}$ catalysts (Fig. 8) show the particles larger (average particles size of $5.5 \mathrm{~nm}$ ) than that observed for the catalysts after reduction step.

In red-C- $\mathrm{Ag}_{2.0} \mathrm{SiBEA}$ silver nanoparticles are well dispersed with the average metal particles size of $3.2 \mathrm{~nm}$ (Fig. 9). Besides of this very small silver nanoparticles, larger $\operatorname{Ag}(0)$ nanoparticles were also observed (Fig. 9). The similar distribution of $\operatorname{Ag}(0)$ nanoparticles was evidenced for spent-red-C-Ag ${ }_{2.0} \operatorname{SiBEA}$ (Fig. 9). It suggests that sintering of $\operatorname{Ag}(0)$ nanoparticles during hydrodechlorination of 1,2-dichloroethane practically did not occur. It seems that this is the reason of high stability of red-C-Ag ${ }_{2.0} \mathrm{SiBEA}$ during HDC process, as shown in Figures $\mathbf{4}$ and $\mathbf{7}$ in chapter 3.3.

HRTEM comparison studies for C- $\mathrm{Ag}_{2.0} \mathrm{HAlBEA}$ and $\mathrm{C}-\mathrm{Ag}_{2.0} \mathrm{SiBEA}$ after reduction at $873 \mathrm{~K}$ and after catalytic run suggest a lower sintering resistance of silver present in red-C$\mathrm{Ag}_{2.0} \mathrm{HAlBEA}$ zeolite catalyst. In contrast, red-C-Ag ${ }_{2.0} \mathrm{SiBEA}$ contains mainly very small silver nanoparticles which are resistant to sintering.

Authors of the earlier works $[18,49]$ devoted to HDC on silver containing catalysts, postulate, that the lack of activity of monometallic silver samples in hydrodechlorination is strongly related with the irreversible adsorption of chlorine species. To explain the cause of unique activity and stability of AgSiBEA additional HRTEM, STEM and EDS-elemental mapping investigations for spent samples were done (Figs 10, 11 and 12). Figs. 10 and 11 show the typical STEM images and EDS-elemental mapping of Ag (blue), $\mathrm{Cl}$ (green), for spent-red-C-Ag ${ }_{2.0} \mathrm{HAlBEA}$ and spent-red-C-Ag $2.0 \mathrm{SiBEA}$. It was shown that very small silver nanoparticles present in both of the catalysts are resistant for chlorination. Ensures this phenomenon, very small silver nanoparticles show unique activity and stability in conversion of 1,2-dichloroethane towards value added product (ethylene) Figs. 6,7,11. Further 
identification of phases (Fig.12) has confirmed phenomenon of the formation of $\mathrm{AgCl}$ from larger silver nanoparticles and chlorine resistance of $<3 \mathrm{~nm} \mathrm{Ag} \mathrm{nanoparticles.}$

\subsection{X-ray diffraction investigation}

The similar X-ray diffractograms of red-C- $\mathrm{Ag}_{2.0} \mathrm{HAlBEA}$, red-C- $\mathrm{Ag}_{2.0} \mathrm{SiBEA}$, spentred-C- $\mathrm{Ag}_{2.0} \mathrm{HAlBEA}$ and spent-red-C- $\mathrm{Ag}_{2.0} \mathrm{SiBEA}$ (Fig. 13) indicate that the calcination, acid treatment as well as reaction condition did not affect crystallinity of zeolite materials.

The introduction of silver into HAlBEA zeolite led to little shift of main, narrow diffraction peak from $2 \theta=22.44^{\circ}$ (for HAlBEA) [21] to $2 \theta=22.52^{\circ}$ (for red-C$\mathrm{Ag}_{2.0} \mathrm{HAlBEA}$ ) (Fig. 13). It indicates that introduction of silver ions in the HAlBEA support and the further calcination and reduction of as prepared $\mathrm{Ag}_{2.0} \mathrm{HAlBEA}$ zeolite do not result in significant changes of BEA structure. In addition, XRD of spent-red-C-Ag ${ }_{2.0} \mathrm{HAlBEA}$ did not show any changes in the position of the main diffraction peak. It indicates the stability of BEA zeolite structure under reaction condition and not as strong interaction of chlorine containing species with acidic active sites as it was observed earlier [21].

Different situation was observed in case of silver catalyst prepared by two-step postsynthesis method. Incorporation of $\mathrm{Ag}$ ions into dealuminated form of BEA led to significant shift of the main diffraction peak from $2 \theta=22.70^{\circ}$ (for SiBEA) [21] to $2 \theta=22.48^{\circ}$ (for red-C-Ag $2.0 \mathrm{SiBEA}$ ) (Fig. 13). This phenomenon suggests that the incorporation of $\mathrm{Ag}^{+}$ ions into vacant-T-atom sites of SiBEA support and the further calcination and reduction of as resulted $\mathrm{Ag}_{2.0}$ SiBEA zeolite led to significant expansion of BEA matrix. For spent-red-C$\mathrm{Ag}_{2.0} \mathrm{SiBEA}$ the position of the main diffraction peak changed only a little to $2 \theta=22.52^{\circ}$ indicated some interaction of chlorine containing species with silver active centres during HDC of 1,2-DCE. 
Moreover, comparative study between XRD results obtained for red-C-Ag ${ }_{2.0} \mathrm{HAlBEA}$, red-C-Ag $2.0 \mathrm{SiBEA}$, spent-red-C-Ag $2.0 \mathrm{HAlBEA}$ and spent-red-C- $\mathrm{Ag}_{2.0} \mathrm{SiBEA}$ have shown that $\mathrm{AgCl}$ is formed under reaction condition on both catalysts (Fig. 13). However, this phenomenon does not affect catalytic activity of red-C-Ag - $2.0 \operatorname{SiBEA}($ Figs. 4,7) that shows the same conversion of 1,2-dichloroethane during more than $66 \mathrm{~h}$ of reaction time. These results are in line with the results obtained by transmission electron microscopy (Figs 8-12), and confirmed the transformation of larger silver nanoparticles into $\mathrm{AgCl}$ (Figs 9-12). Thereby, they confirmed the beneficial role of very small nanoparticles of silver, resistant to deactivation in hydrodechlorination of 1,2-dichloroethane.

\section{Conclusions}

The investigations carried out in this work have revealed the unique activity of monometallic silver containing zeolite catalysts in the conversion of 1,2-dichloroethane into value added products. The role of silver in red-C-Ag ${ }_{2.0} \mathrm{SiBEA}$ and red-C-Ag ${ }_{2.0} \mathrm{HAlBEA}$ was different.

We have showed, that the excellent activity of silver catalyst prepared by two-step postsynthesis method in the conversion of 1,2-DCE (with $100 \%$ selectivity to ethylene) is strongly related to the presence of very small $(<3 \mathrm{~nm})$ silver nanoparticles in red-C$\mathrm{Ag}_{2.0} \mathrm{SiBEA}$, resistant to deactivation.

On the other hand, the activity of red-C-HAlBEA support and red-C-Ag ${ }_{2.0} \mathrm{HAlBEA}$ material is related to the presence in both catalysts strong Brønsted acidic centres that played key role in conversion of 1,2-dichloroethane to vinyl chloride (100\% selectivity).

\section{Acknowledgements}


Project funded by the Foundation for Polish Science, POMOST/2011-4/11 co-financed by the EU European Regional Development Fund (AŚ, SD). Special thanks for Ilona Zielińska for participation in the catalytic experiments.

\section{References}

1. B. Huang, Ch. Lei, Ch. Wei, G. Zeng, Environ Int 71 (2014) 118-138

2. L.E. Manzer, V.N. Rao, Adv. Catal. 39 (1993) 329-350

3. M. Wu et al. Catal. Commun. 18 (2012) 72-75

4. R. López-Fonseca, J. I. Gutiérrez-Ortiz, J. L. Ayastui, M.A. Gutiérrez-Ortiz, J. R. González-Velasco, Appl. Catal. B 45 (2003) 13-21

5. S. Pitkäaho, T. Nevanperä, L. Matejova, S. Ojala, R. L. Keiski, Appl. Catal. B: 138139 (2013) 33-42

6. Y-F Wang, W-J. Lee, Ch-Y Chen., J. Aerosol Sci. 28, Suppl. 1, (1997)

7. P.H. Taylor, B. Dellinger, J. Anal. Appl. Pyrolysis 49 (1999) 9-29

8. J. Kawabata, I.A. Take, Y. Ohishi, T. Shishido, Y. Tiaw, K. Takachi, K. Takeshira, Appl. Catal. B 66: (2006) 151-160

9. Y. Cesteros, P. Salagre, F. Medina, J.E. Sueiras, Catal Lett. 79 (2002) 83-88

10. N. Martín, A. López-Gaona, M. Viniegra, P. Villamil, G. Córdoba, Reac. Kinet. Mech. Catal. 101 (2010) 491-500

11. N. Barrabès, K. Fottinger, J. Llorca, A. Dafinov, F. Medina, J. Sa, C. Hardacre, G. Rupprechter, J. Phys. Chem. C 114 (2010) 17675-17682

12. B.T Meshesha, N. Barrabes, J. Llorcac, A. Dafinov, F. Medina, K. Fottinger, Appl. Catal. B 117- 118 (2012) 236-245

13. A. Śrebowata, W. Lisowski, J.W. Sobczak, Z. Karpiński, Catal. Today 175 (2011) $576-584$ 
14. B.T. Meshesha, N. Barrabes, K. Fottinger, R.J. Chimentao, J. Llorca, F. Medina, G. Rupprechter, J.E. Sueiras, Appl. Catal. A 453 (2013) 130-141

15. X. Wei, A. Wang, X. Yang, L. Li, T. Zhang, Appl. Catal. B 121-122 (2012) 105-114

16. Y. Han, J. Zhou, W. Wang, H. Wan, Z. Xu, Sh. Zheng, D. Zhu, Appl. Catal. B 125 (2012) 172-179

17. P P. Kulkarni, V. I. Kovalchuk, J. L. d'Itri, Appl. Catal. B 36 (2002) 299-309

18. S. Lambert, F. Ferauche, A. Brasseur, J.-P. Pirard, B. Heinrichs, Catal. Today 100 (2005) 283-289

19. K.V.R. Chary, P.V.R. Rao, V.V. Rao, Catal. Commun. 9 (2008) 886-893

20. A. Śrębowata, W. Juszczyk, Z. Kaszkur, J.W. Sobczak, L. Kępiński, Z. Karpiński, Appl. Catal. A 319 (2007) 181-192

21. A. Śrębowata, R. Baran, D. Łomot,D. Lisovytskiy, T. Onfroy, S. Dzwigaj, Appl. Catal. B 147 (2014) 208-220

22. S. Lambert, A. Brasseur, J.P. Pirard, B. Heinrichs, Appl. Catal. A 270 (2004) 201-208.

23. A. Śrębowata, R. Baran, S. Casale, I. I. Kamińska, D. Łomot, D. Lisovytskiy, S. Dzwigaj, Appl. Catal. B 152-153 ( 2014) 317-327

24. A. Śrębowata, W. Juszczyk, Z. Kaszkur, Z. Karpiński, Catal. Today124 (2007) 28-35

25. H. Lee, S.J. Schmieg, S.H. Oh, Appl. Catal. A 342 (2008) 78-86

26. N. Popovych, P. Kyriienko, S. Soloviev, S. Orlyk, S. Dzwigaj, Micropor. Mesopor. Mater. 203 (2015) 163-169

27. L. Gang, B.G. Anderson, J. van Grondelle, R.A. van Santen, Appl. Catal. B 40 (2003) $101-110$

28. E. Kolobova, A. Pestryakov, A. Shemeryankina, Y. Kotolevich, O. Martynyuk, H.J. Tiznado Vazquez, N. Bogdanchikova, Fuel 138 (2014) 65-71

29. T. C.R. Rocha, M. Hävecker, A. Knop-Gericke, R. Schlögl, J. Catal. 312 (2014), 12-16 
30. P. Claus, H. Hofmeister, J. Phys.Chem. B 103 (1999) 2766-2775

31. H. Zea, K.Lester ,A.K. Datye, E. Rightor, R. Gulotty, W. Waterman ,M. Smith, Appl. Catal. A $282(2005)$ 237-245

32. N. Job, B. Heinrichs, F. Ferauche, F. Noville, J. Marien, J-P Pirard, Catal. Today 102103 (2005) 234-241

33. A. Śrębowata, I. Zielińska, R. Baran, G. Słowik, S. Dzwigaj. Catal.Commun. 69 (2015) $154-160$

34. R. Seifert, R. Rytz, G. Calzaferri, J. Phys. Chem. A 104 (2000) 7473-7483

35. G. Calzaferri, C. Leiggener, S. Glaus, D. Schürch, K. Kuge, Chem. Soc. Rev. 32 (2003) 29-37

36. J. Shibata, K. Shimizu, Y. Takada, A. Shichi, H. Yoshida, S. Satokawa, A. Satsuma, T. Hattori, J. Catal. 227 (2004) 367-374

37. A. Satsuma, J. Shibata, A. Wada, Y. Shinozaki, T. Hattori, Stud. Surf. Sci. Catal. 145 (2003) $235-238$

38. Ch. Hu, T. Peng, X. Hu, Y. Nie, X. Zhou, J. Qu, H. He J. Am. Chem. Soc. 2010, 132, $857-862$

39. K. Sato, T. Yoshinari, K. Kintaichi, M. Haneda, H. Hamada, Appl. Catal. B. 44 (2003) 67-78

40. M. Matsuoka, E.Matsuda, K. Tsuji, H. Yamashita, M. Anpo, J. Mol. Catal. A 107 (1996) 399-403

41. J. Texter, T. Gonsiorowski, R. Kellerman, Phys. Rev. B. 23 (1981) 4407-4418

42. S. Dzwigaj, N. Popovych, P. Kyriienko, J.-M. Krafft, S. Soloviev, Micropor. Mesopor. Mater. 182 (2013) 16-24

43. K. Fuku, R. Hayashi, S. Takakura, T. Kamegawa, K. Mori, H. Yamashita, Angew. Chem. Int. Ed. 2013, 52, $7446-7450$ 
44. D. Chen, Z. Qu, S. Shen, X. Li, Y. Shi, Y. Wang, Q. Fu, J. Wu, Catal. Today 175 (2011) 338-345

45. S.G. Aspromonte, E.E. Miró, A.V. Boix, Adsorption 18 (2012) 1-12

46. S.C. Shekhar, J.K. Murthy, P.K. Rao, K.S.R. Rao, Appl. Catal. A: Gen. 271 (2004) $527 ; 95-101$

47. E.V. Golubina, E.S. Lokteva, V.V. Lunin, N.S. Telegina, A.Yu. Stakheev, P. Tundo, Appl. Catal. A: Gen. 302 (2006) 32-41

48. V.I. Simagina, O.V. Netskina, E.S.Tayban, O.V. Komova, E.D. Grayfer, A.V. Ischenko, E.M. Pazhetnov, Appl. Catal. A: Gen. 379 (2010) 87-94

49. S. L. Pirard, J-P. Pirard, G. Heyen, J-P. Schoebrechts, B. Heinrichs, Chem. Eng. J. 173 (2011) 801- 812

50. N. S. Babu, N. Lingaiah, Nayeem Pasha, J. Vinod Kumar, P.S. Sai Prasad, Catal. Today, 141 (2009) 120-124

51. M. Bonarowska, Z. Kaszkur, L. Kępiński, Z. Karpiński Appl. Catal. B 99 (2010) 248256

52. S. Gómez-Quero, F. Cárdenas-Lizana , M. A. Keane, J. Catal. 303 (2013) 41-49. 


\section{Figure captions}

Figure 1. DR UV-vis spectra recorded at ambient atmosphere of as prepared ( $\left.\mathrm{Ag}_{2.0} \mathrm{HAlBEA}\right)$, calcined (C-Ag $2.0 \mathrm{HAlBEA}$ ) and further reduced (red-C-Ag ${ }_{2.0} \mathrm{HAlBEA}$ ) Ag-containing HAlBEA.

Figure 2. DR UV-vis spectra recorded at ambient atmosphere of as prepared $\left(\mathrm{Ag}_{2.0} \mathrm{SiBEA}\right)$, calcined (C-Ag $2.0 \mathrm{SiBEA})$ and further reduced (red-C-Ag $2.0 \mathrm{SiBEA}) \mathrm{Ag}$-containing SiBEA.

Figure 3. Temperature programmed reduction profiles of $\mathrm{C}-\mathrm{Ag}_{2.0} \mathrm{HAlBEA}$ and $\mathrm{C}$ $\mathrm{Ag}_{2.0} \mathrm{SiBEA}$.

Figure 4. Time on stream behavior of red-C-HAlBEA, red-C-Ag $2.0 \mathrm{HAlBEA}$, red-C-SiBEA, and red-C-Ag2.0SiBEA catalysts in hydrodechlorination of 1,2-dichloroethane at $523 \mathrm{~K}$ : overall conversion.

Figure 5. Time on stream behavior of red-C-HAlBEA, red-C-Ag ${ }_{2.0} \mathrm{HAlBEA}$, red-C-SiBEA, and red-C- $\mathrm{Ag}_{2.0} \mathrm{SiBEA}$ catalysts in hydrodechlorination of 1,2-dichloroethane at $523 \mathrm{~K}$ : vinyl chloride selectivity.

Figure 6. Time on stream behavior of red-C-HAlBEA, red-C-Ag ${ }_{2.0} \mathrm{HAlBEA}$, red-C-SiBEA, and red-C-Ag ${ }_{2.0} \mathrm{SiBEA}$ catalysts in hydrodechlorination of 1,2-dichloroethane at $523 \mathrm{~K}$ : ethylene selectivity.

Figure 7. Time on stream behavior of red-C-Ag${ }_{2.0} \mathrm{SiBEA}$ catalyst in long term hydrodechlorination of 1,2-dichloroethane at $523 \mathrm{~K}$ : ethylene selectivity and overall conversion.

Figure 8. HRTEM images and silver nanoparticle size distribution of red-C-Ag ${ }_{2.0} \mathrm{HAlBEA}$ and spent-red-C-Ag $2.0 \mathrm{HAlBEA}$.

Figure 9. HRTEM images and silver nanoparticle size distribution of red-C- $\mathrm{Ag}_{2.0} \mathrm{SiBEA}$ and spent-red-C-Ag $2.0 \mathrm{SiBEA}$. 
Figure 10. STEM images with EDS elemental mapping for spent-red-C-Ag ${ }_{2.0} \mathrm{HAlBEA}$.

Figure 11. STEM images with EDS elemental mapping for spent-red-C-Ag ${ }_{2.0} \mathrm{SiBEA}$.

Figure 12. HRTEM images with identification of $\mathrm{Ag}$ and $\mathrm{AgCl}$ phases for spent-red-C$\mathrm{Ag}_{2.0} \mathrm{HAlBEA}$ and spent-red-C-Ag 2.0 $\mathrm{SiBEA}$.

Figure 13. XRD patterns of red-C-Ag 2 $_{2.0} \mathrm{HAlBEA}$, spent-red-C-Ag ${ }_{2.0} \mathrm{HAlBEA}$, red-C$\mathrm{Ag}_{2.0} \mathrm{SiBEA}$ and spent-red-C-Ag ${ }_{2.0} \mathrm{SiBEA}$. Circles indicate positions of XRD reflections of $\mathrm{Ag}$ (111), triangles symbolize positions of XRD reflections of $\mathrm{AgCl}$ (002). 


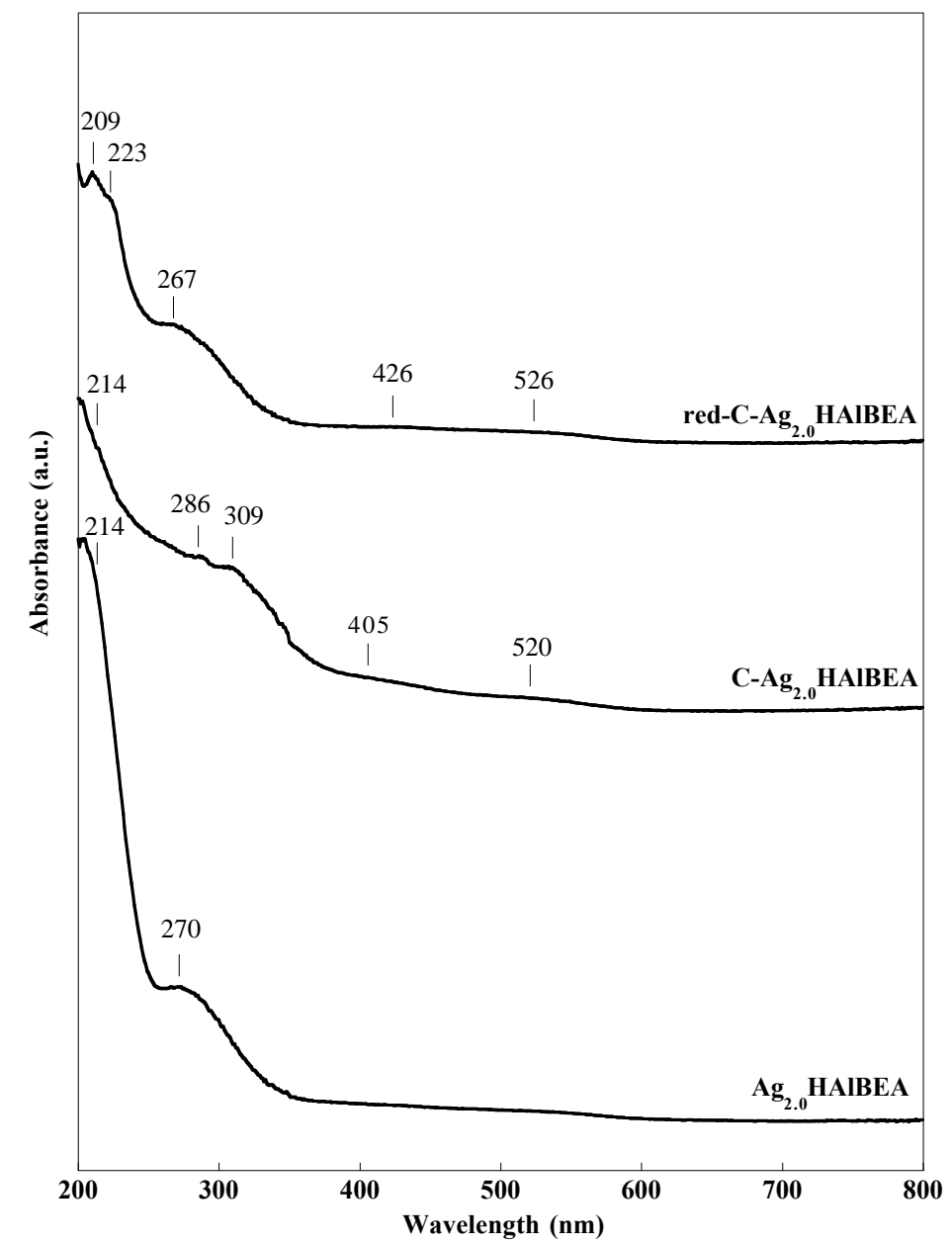

Figure 1 


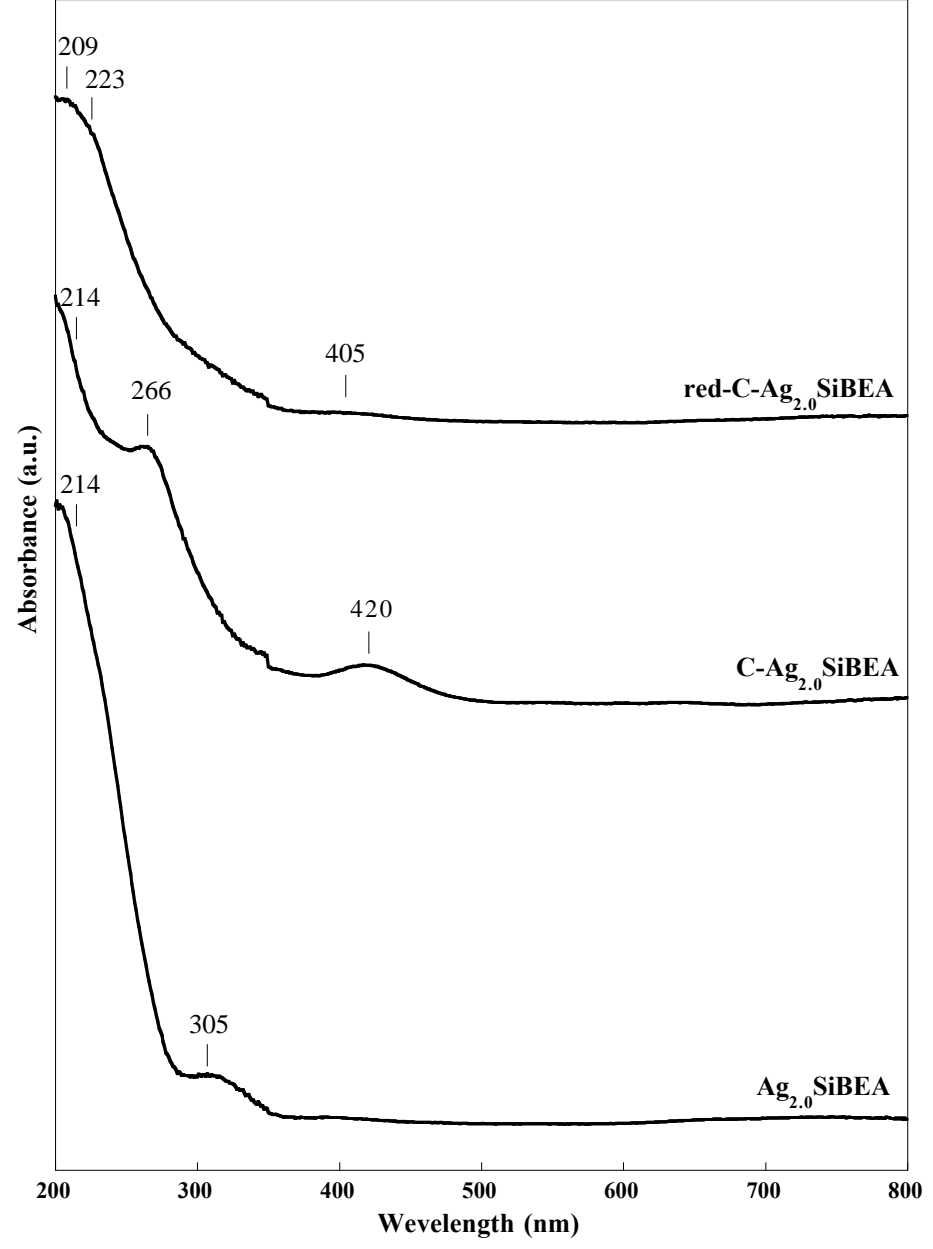

Figure 2 


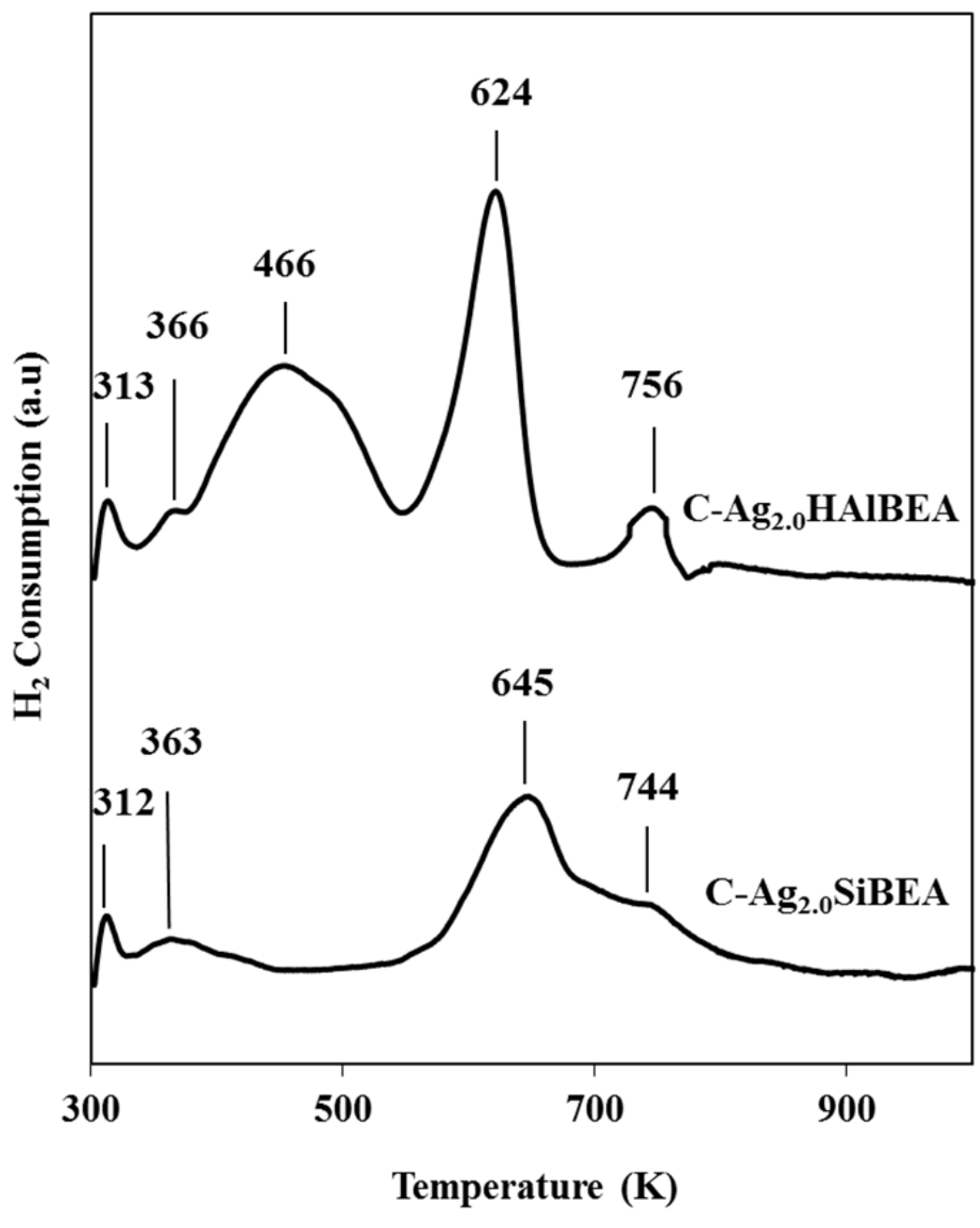

Figure 3 


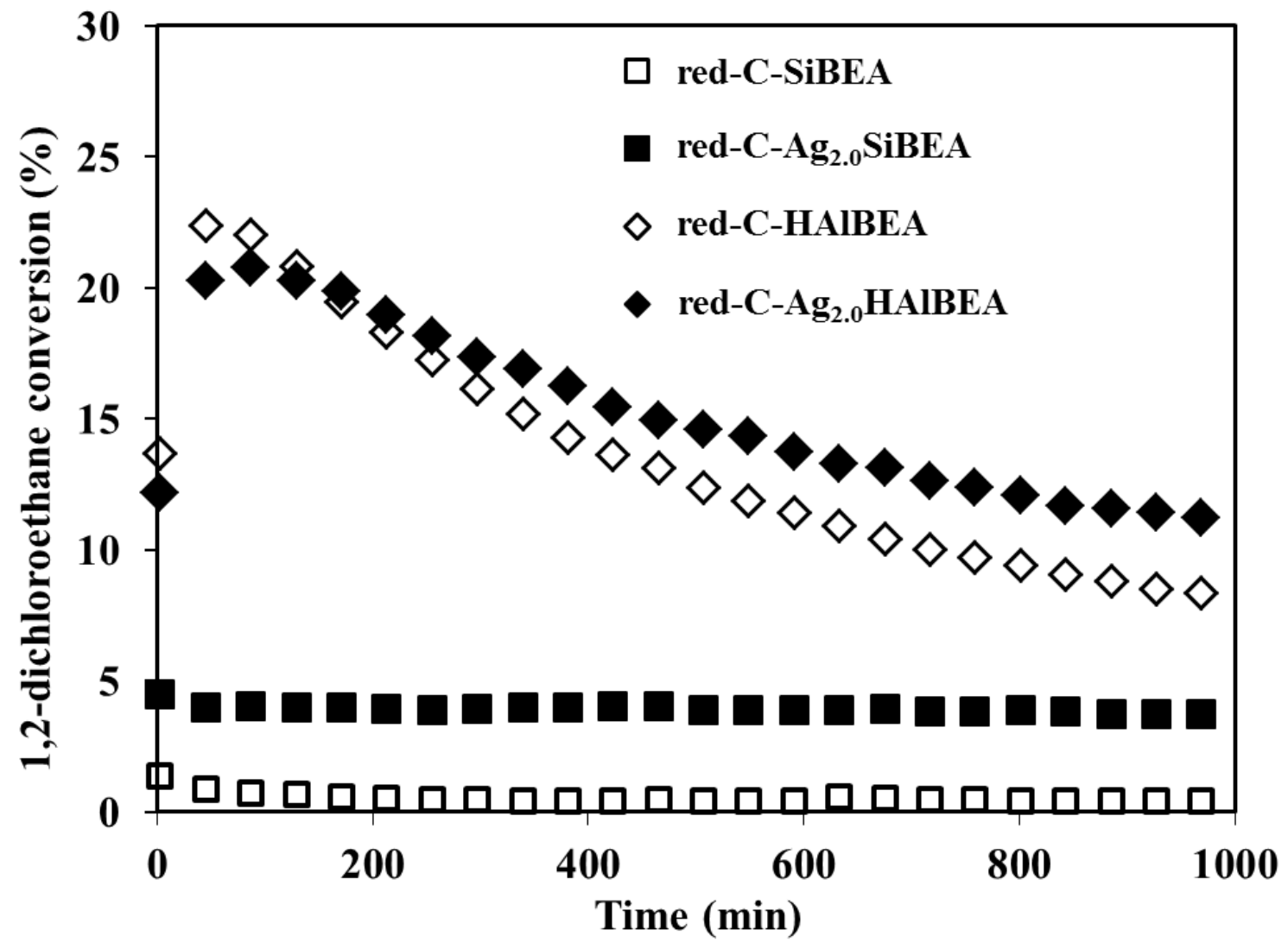

Figure 4 


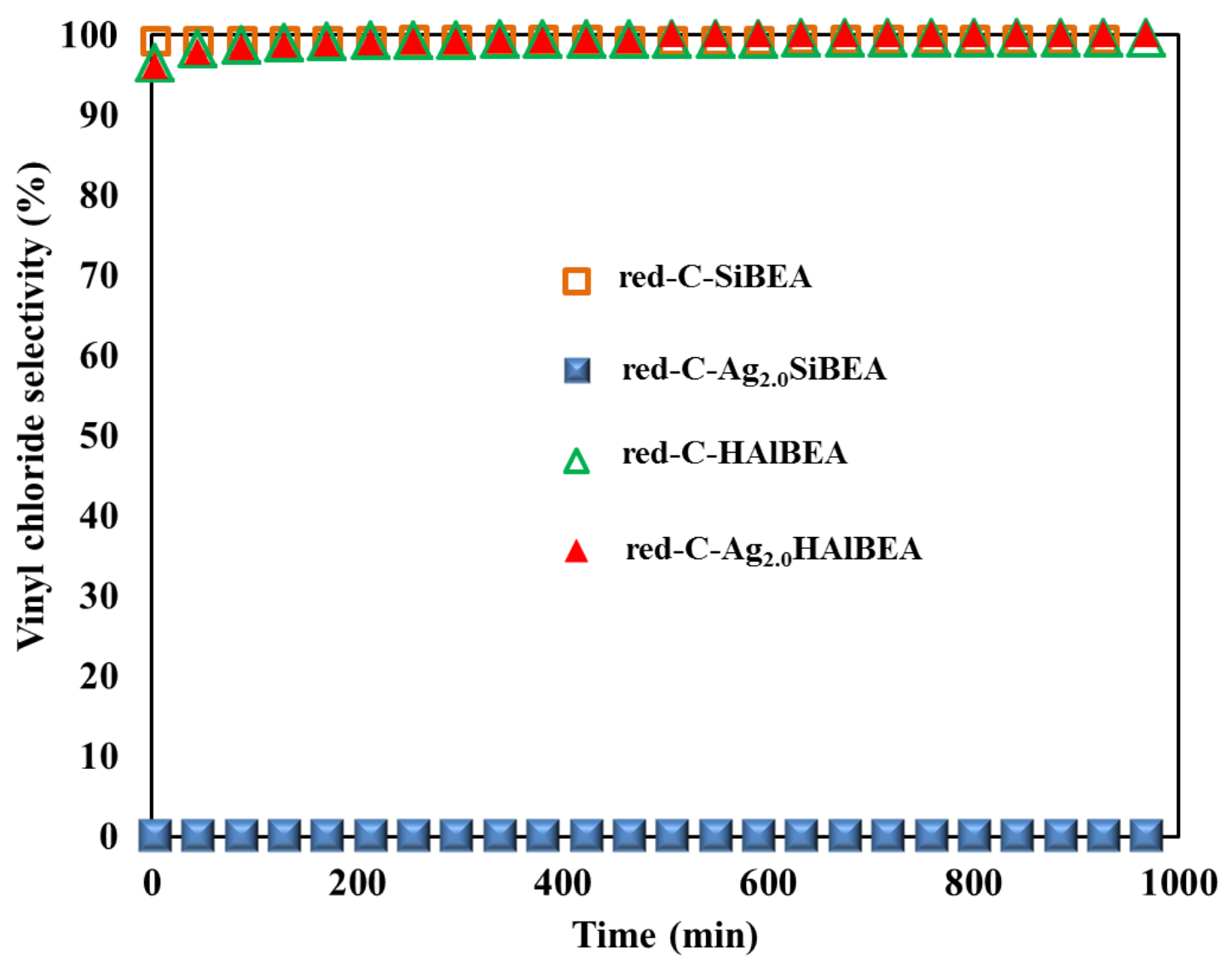

Figure 5 


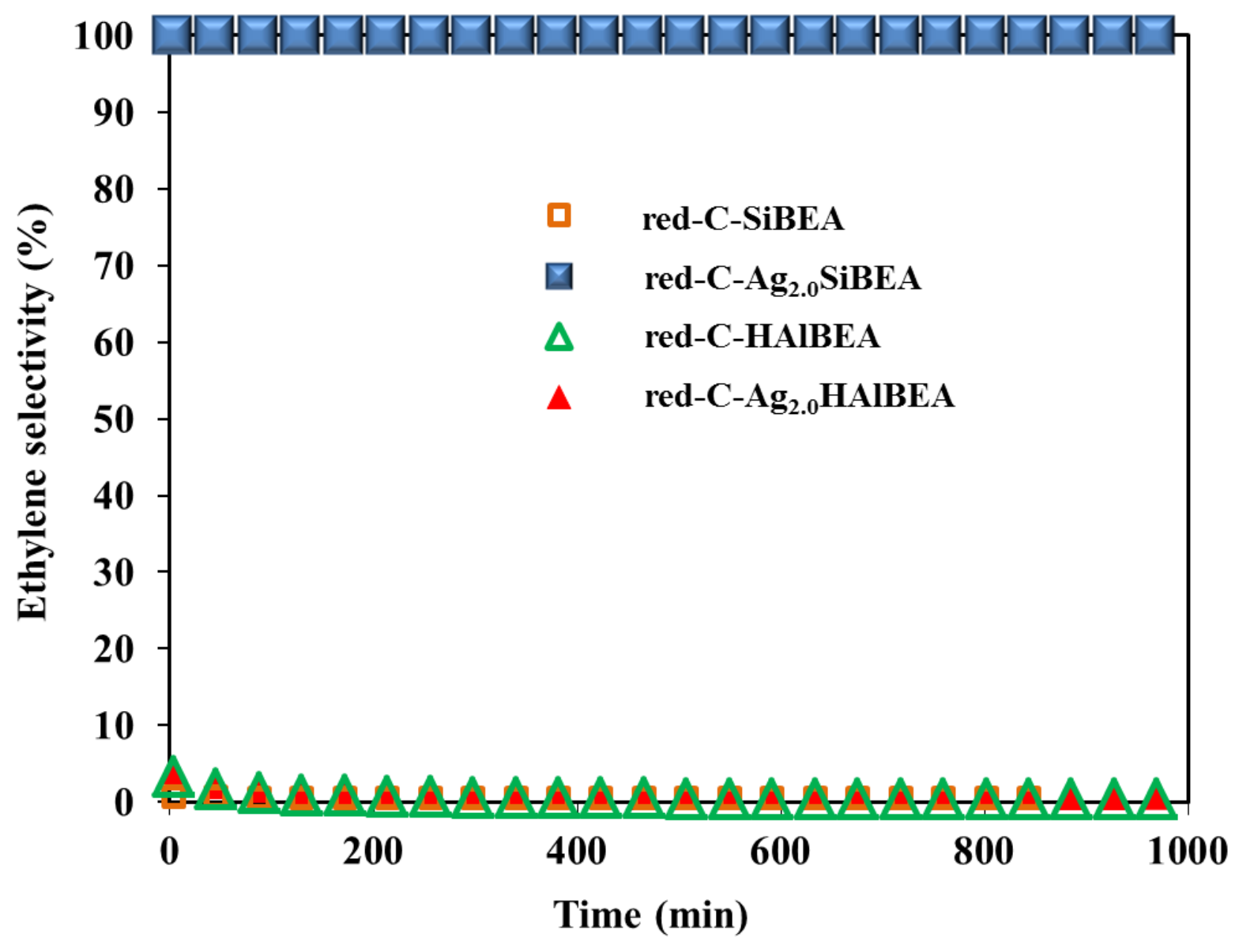

Figure 6 


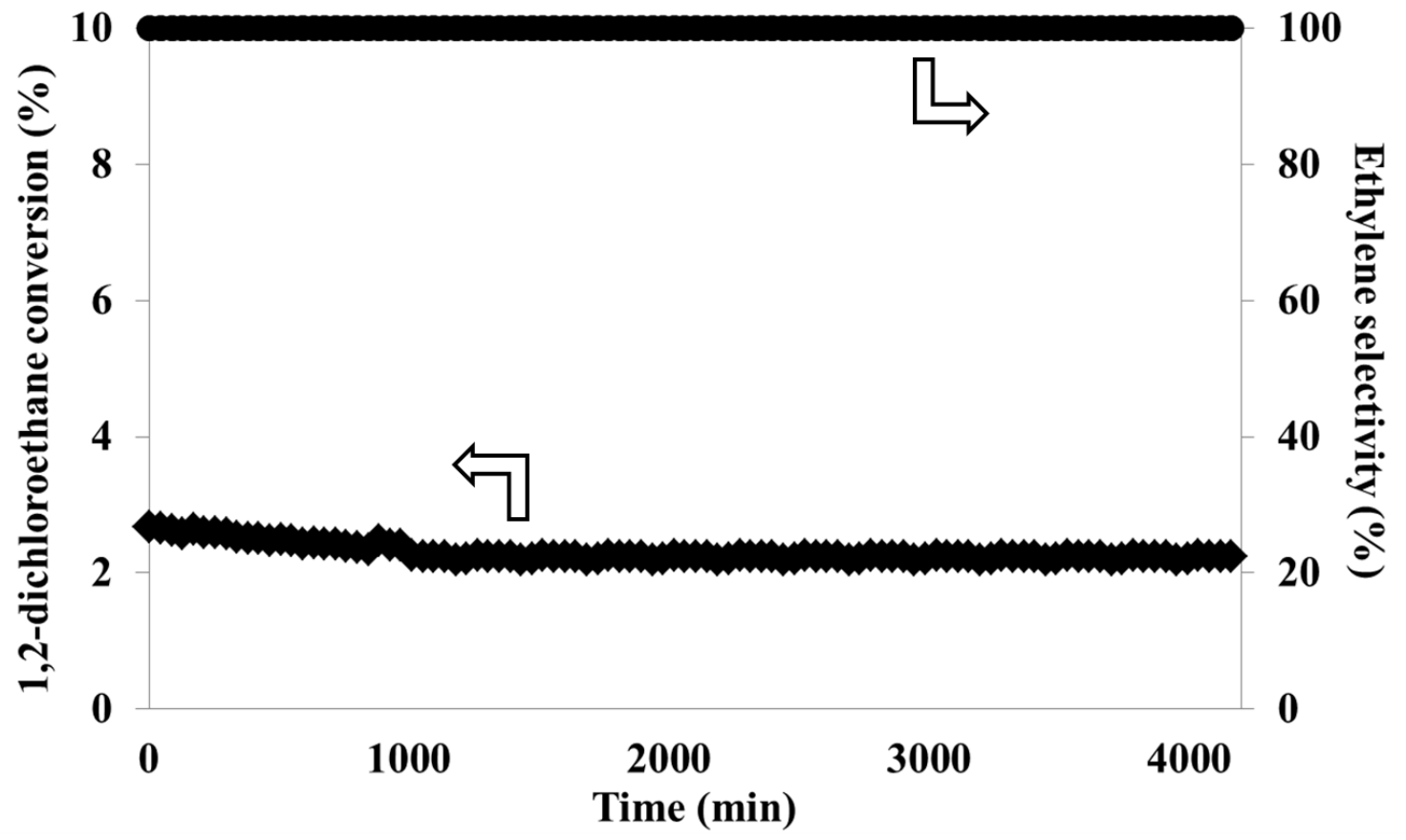

Figure 7 

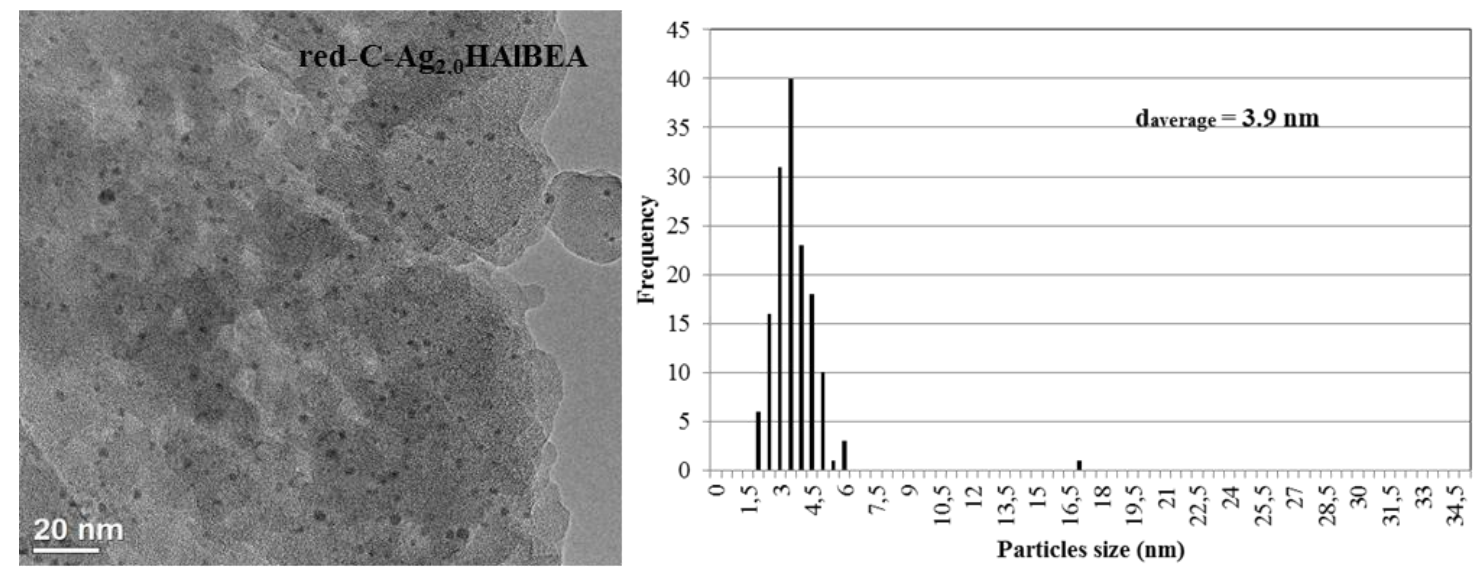

spent-red-C-Ag ${ }_{2.0}$ HAIBEA

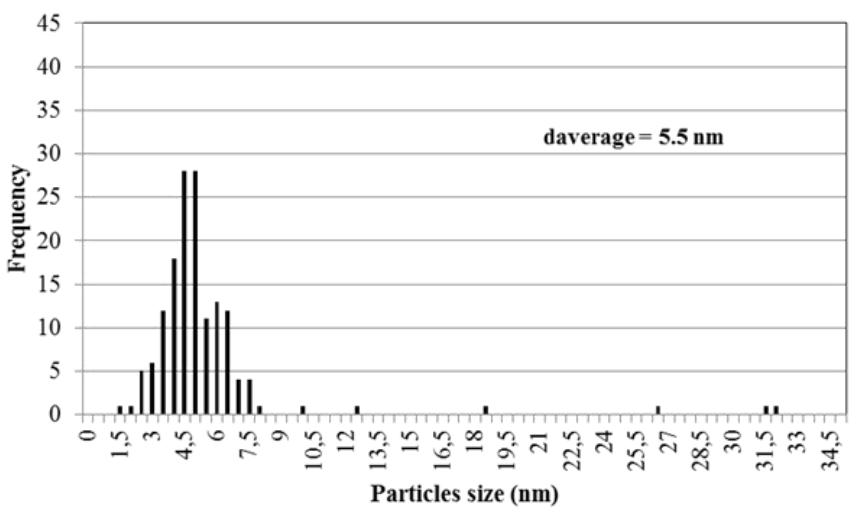

Figure 8 

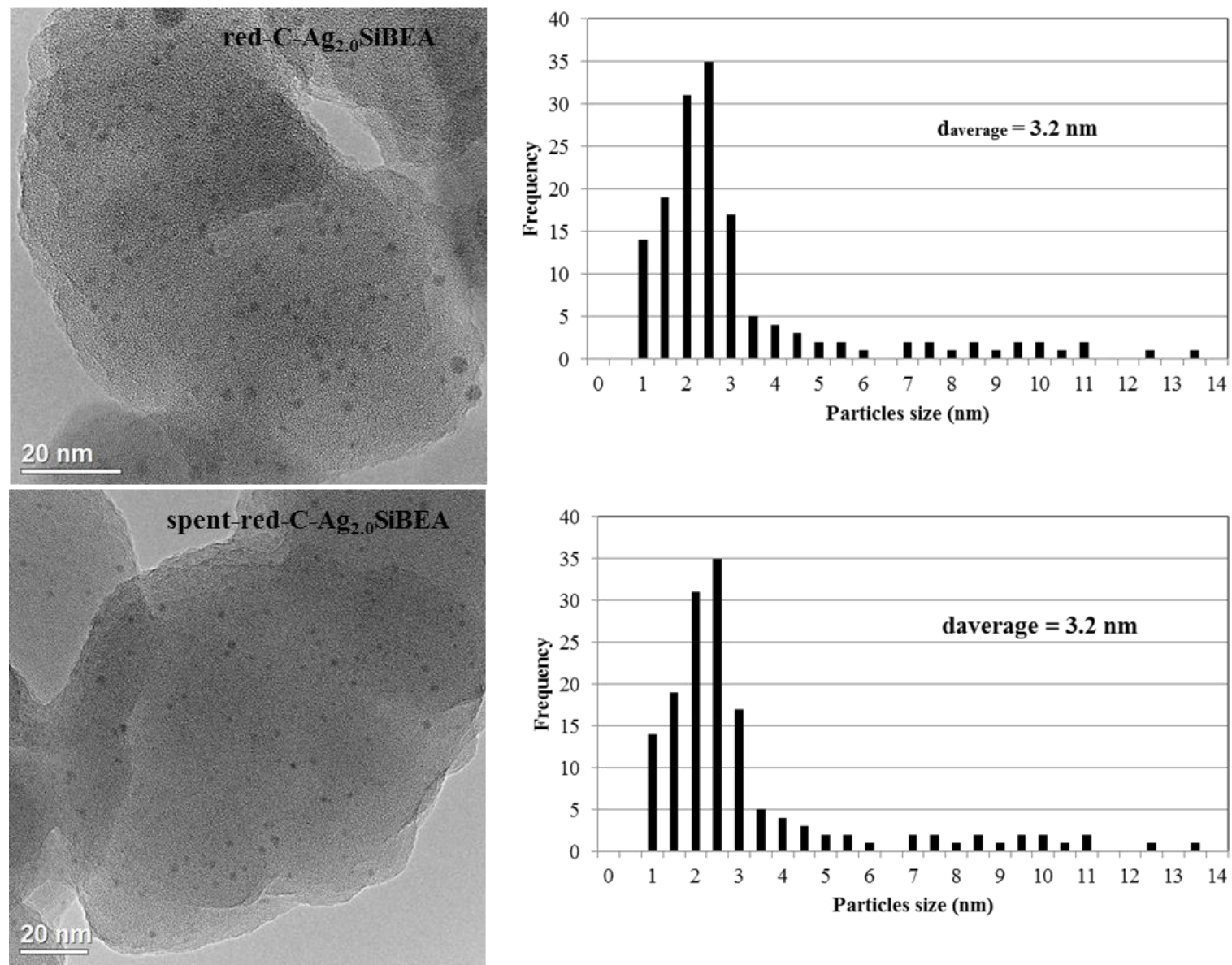

Figure 9 

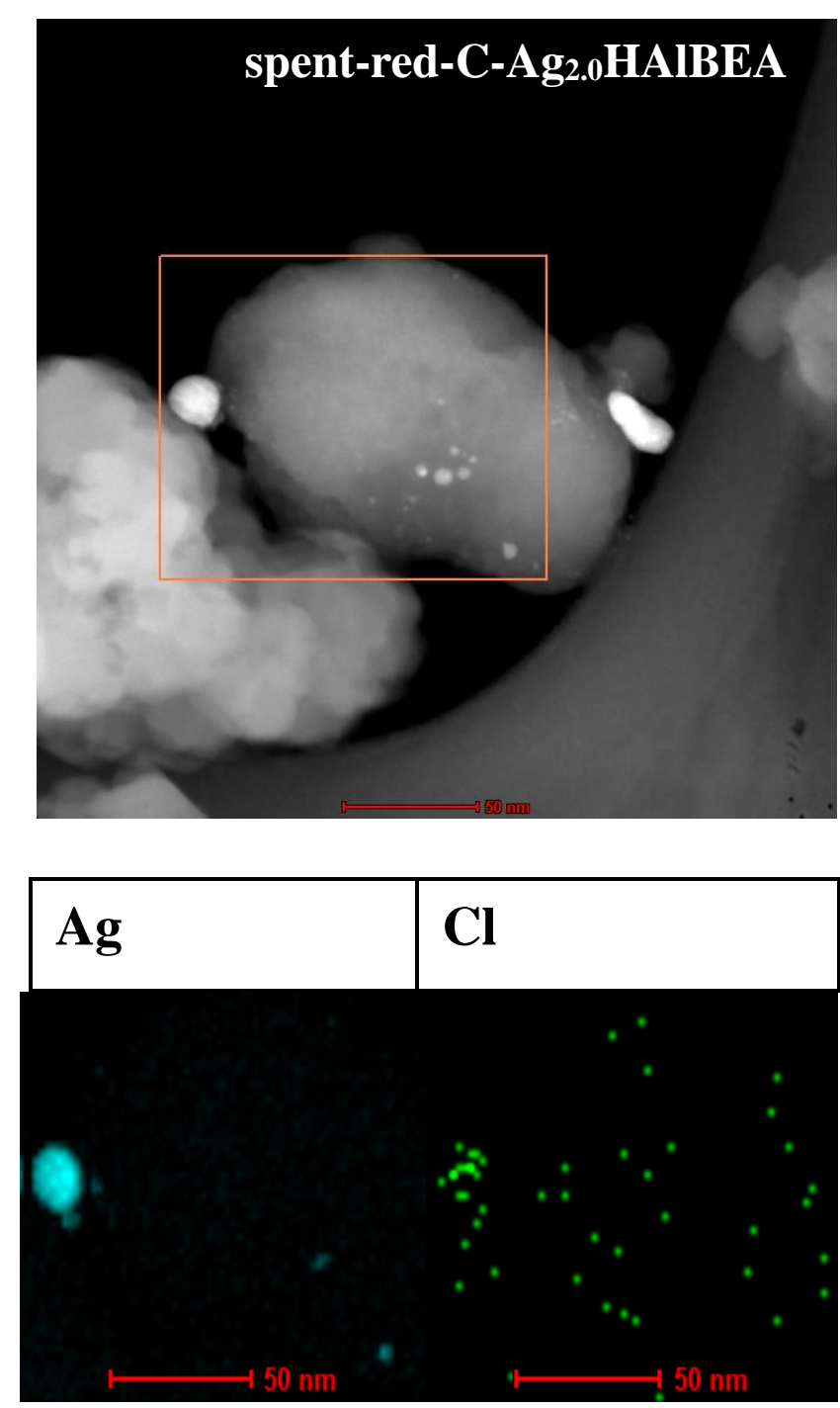

Figure 10 

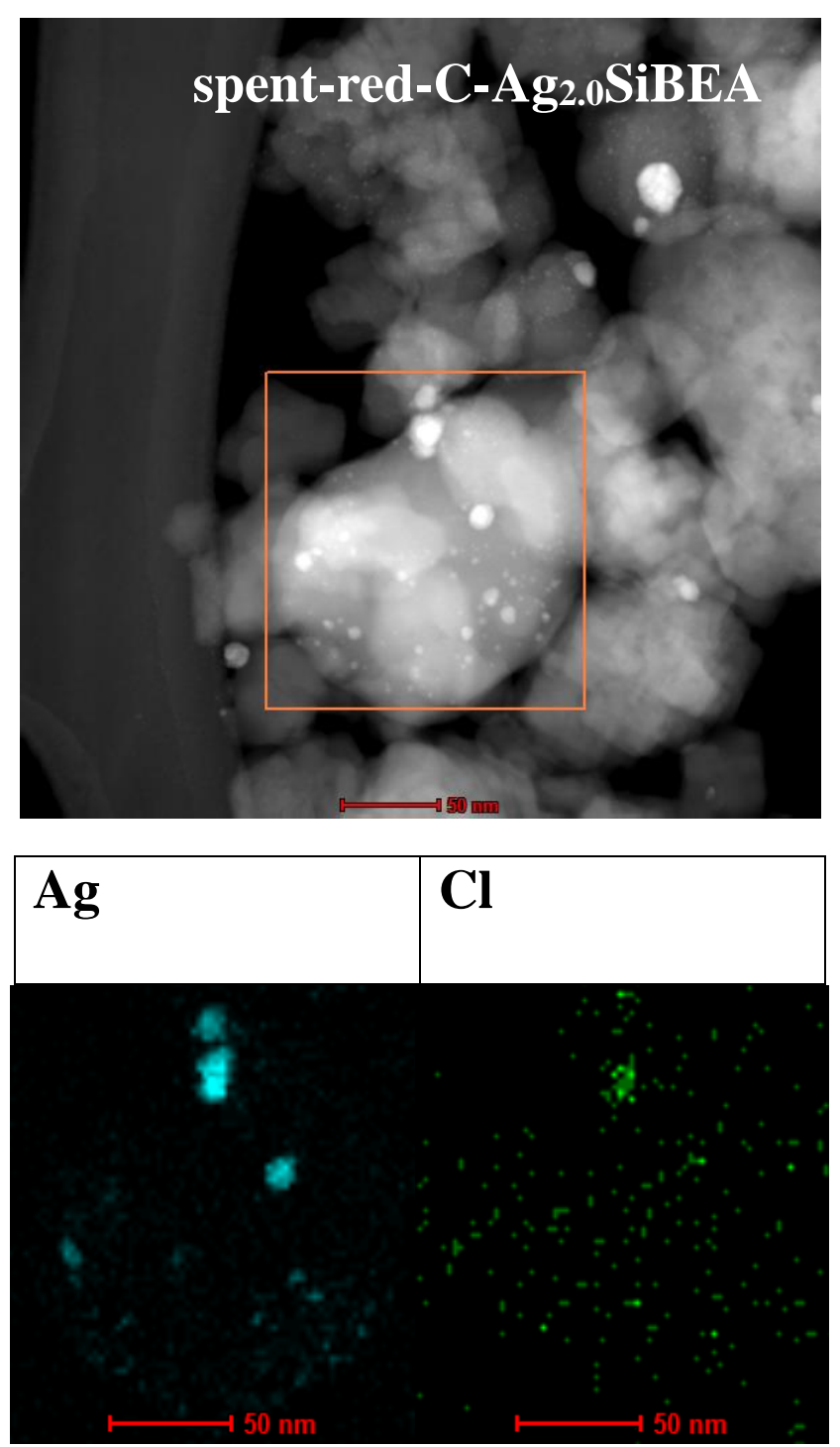

Figure 11 


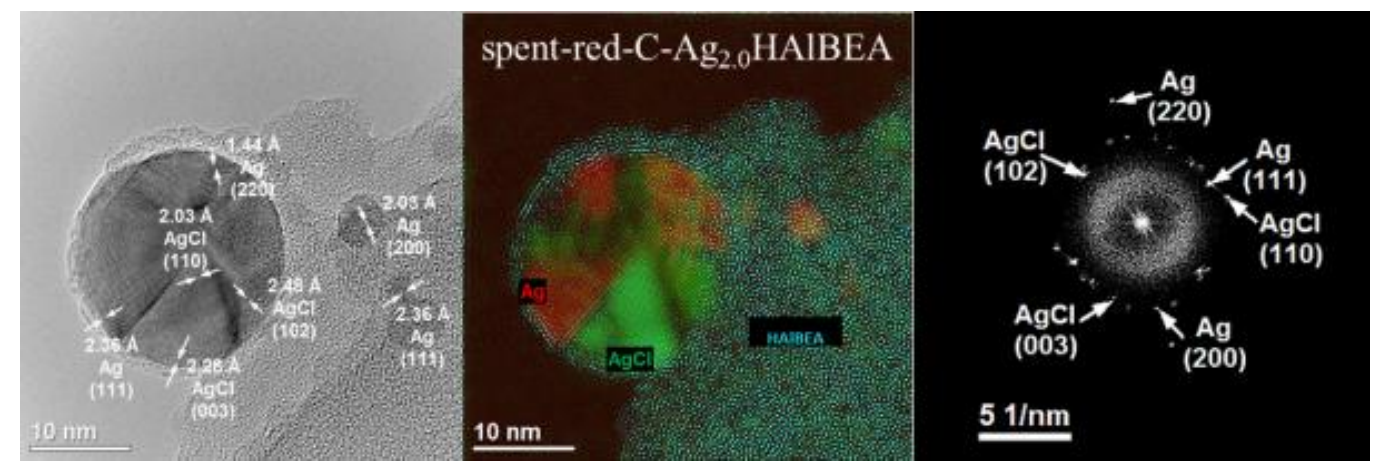

Figure 12 


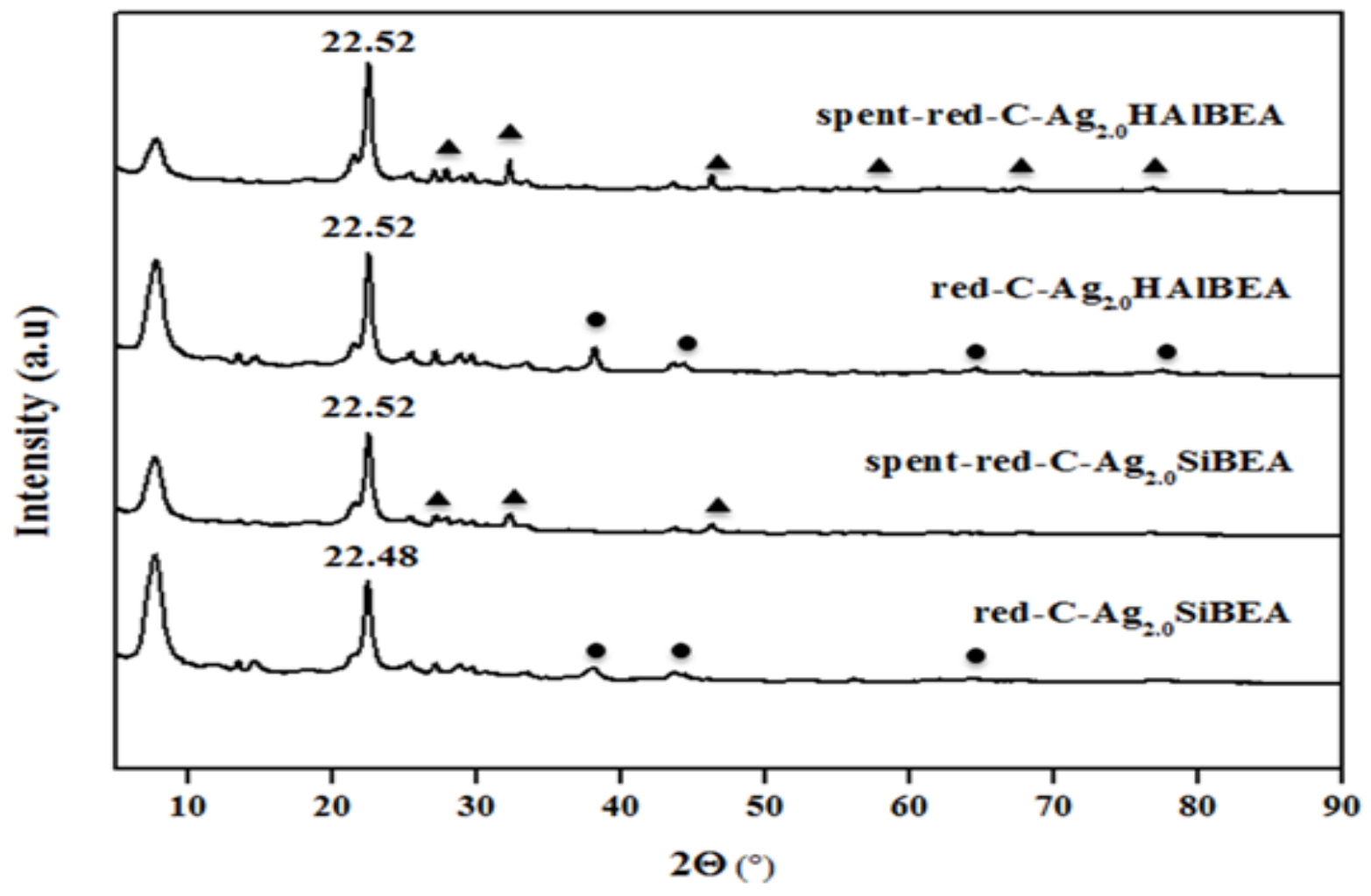

Figure 13 